\title{
Readthrough Strategies for Therapeutic Suppression of Nonsense Mutations in Inherited Metabolic Disease
}

\author{
B. Pérez P. Rodríguez-Pombo M. Ugarte L.R. Desviat
}

Centro de Diagnóstico de Enfermedades Moleculares, y Centro de Biología Molecular Severo Ochoa, UAM-CSIC, Centro de Investigación Biomédica en Red de Enfermedades Raras (CIBERER), y Instituto de Investigación Hospital Universitario La Paz (IDIPaz), Madrid, España

\section{Key Words}

Aminoglycosides $\cdot$ Ataluren $\cdot$ Inherited metabolic disease $\cdot$ Nonsense mutations $\cdot$ Readthrough drugs $\cdot$ Suppression therapy

\begin{abstract}
Inherited metabolic diseases (IMDs) belong to the group of rare diseases due to their low individual prevalence. Most of them are inherited in autosomal recessive fashion and represent good candidates for novel therapeutical strategies aimed at recovering partial enzyme function as they lack an effective treatment, and small levels of enzymatic activity have been shown to be associated with improved outcome and milder phenotypes. Recently, a novel therapeutic approach for genetic diseases has emerged, based on the ability of aminoglycosides and other compounds in allowing translation to proceed through a premature termination codon introduced by a nonsense mutation, which frequently constitute a significant fraction of the mutant alleles in a population. In this review we summarize the essentials of what is known as suppression therapy, the different compounds that have been identified by high-throughput screens or developed using a medicinal chemistry approach and the preclinical and clinical trials that are being conduct-
\end{abstract}

ed in general and in the field of IMDs in particular. Several IMDs have shown to be good models for evaluating readthrough compounds using patients' cells carrying nonsense mutations, monitoring for an increase in functional recovery and/or enzyme activity. Overall, the positive results obtained indicate the feasibility of the approach for different diseases and although the levels of protein function reached are low, they may be enough to alleviate the consequences of the pathology. Nonsense suppression thus represents a potential therapy or supplementary treatment for a number of IMD patients encouraging further clinical trials with readthrough drugs with improved functionality and low toxicity.

Copyright $\odot 2012$ S. Karger AG, Basel

In the past decade, remarkable advances in the ability to treat genetic disorders have been made, in the context of what is known as personalized genetic medicine that aims to treat patients according to their specific genetic defects and molecular phenotypes. The situation has specifically changed in the field of rare diseases, defined in the EU as those with a prevalence under 5 cases for every 10,000 inhabitants. Many of these rare genetic pathologies are severe, with high mortality and morbidity and

\section{KARGER \\ Fax +4161306 1234 \\ E-Mail karger@karger.ch}

www.karger.com
(C) 2012 S. Karger AG, Basel

1661-5425/12/0035-0230\$38.00/0

Accessible online at:

www.karger.com/msy
Lourdes R. Desviat

Centro de Biología Molecular Severo Ochoa

Universidad Autónoma de Madrid

Nicolás Cabrera 1, ES-28049 Madrid (Spain)

Tel. +34 91196 4566, E-Mail lruiz@cbm.uam.es 
Fig. 1. Overview of the steps in the expression of PTC alleles resulting from nonsense mutations and of the suppression therapy using readthrough drugs. Genes with a nonsense mutation are transcribed, producing a PTC-bearing transcript that is degraded by the NMD mechanism if the PTC is $>50-55$ nucleotides upstream of an exon junction complex (EJC). Remaining transcripts result in truncated proteins devoid of activity. In the presence of readthrough drugs, translation proceeds over the PTC, resulting in a full-length protein which can be functional or non-functional, depending on the amino acid inserted at the PTC. Some aminoglycosides have been reported to stabilize mRNA, thus increasing the pool of transcripts available for readthrough [Bellais et al., 2010].

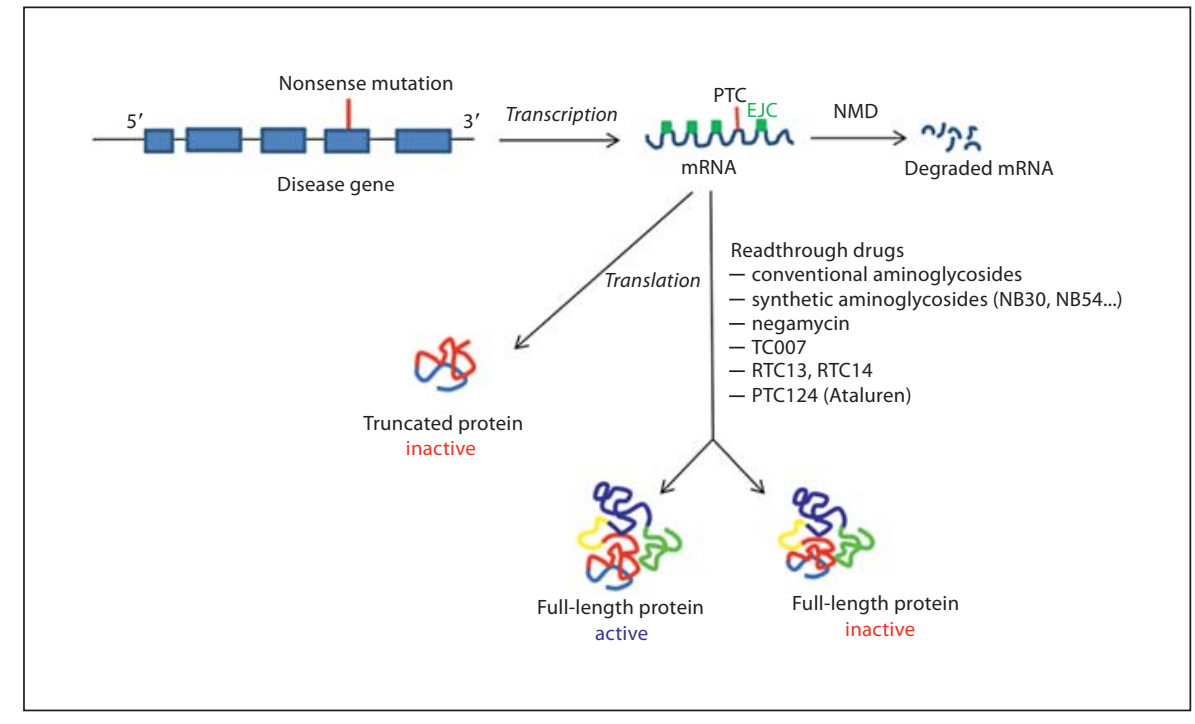

most often they lack effective and specific treatment. This fact and the increasing knowledge of molecular mechanisms of disease-causing mutations has boosted the search for mutation-targeted molecular therapies that can be developed for the benefit of individuals affected by rare diseases, but which also have the potential for broadening their application to the treatment of more common disorders.

In this context, extensive genotyping in different genes has revealed that in most diseases a substantial fraction of patients, generally ranging between 10 and $30 \%$, are carriers of nonsense mutations (HGMD Professional Release 2011: http://www.hgmd.cf.ac.uk/ac/index. php) [Mort et al., 2008], which introduce a premature termination codon (PTC) in the mRNA that is in turn degraded by the nonsense-mediated mRNA decay (NMD) pathway [Kuzmiak and Maquat, 2006]. NMD acts as a quality-control surveillance mechanism that selectively degrades mRNAs harboring PTCs to prevent the synthesis of truncated proteins with potential dominant-negative or toxic gain-of-function activities. Recognition of a stop codon as premature involves a protein complex known as exon junction complex (EJC) that is deposited on mRNAs during splicing. Interaction between the EJC and NMD factors assembled at the PTC after a pioneer round of translation triggers the degradation of the transcript [Chang et al., 2007]. An experimentally defined rule indicates that NMD is triggered by PTCs located $>50-55$ bp upstream of an EJC, although several exceptions have been described [Asselta et al.,
2001]. Thus, nonsense mutations generally result in low levels of transcripts encoding a truncated protein devoid of activity and so are considered mutations of severe effect (fig. 1). However, the discovery that aminoglycoside antibiotics induce nonsense mutation readthrough and thus synthesis of functional full-length protein in cystic fibrosis [Howard et al., 1996; Bedwell et al., 1997] resulted in the development of what is called nonsense suppression therapy, using low-molecular-weight compounds to induce the translation machinery to recode a nonsense codon into a sense one [Keeling and Bedwell, 2011] (fig. 1). These compounds, known as readthrough drugs, induce the binding of a near-cognate aminoacyltRNA to the PTC and the subsequent transfer of the corresponding amino acid to the nascent polypeptide, thus allowing translation to proceed in the correct reading frame to produce a full-length polypeptide. Nonsense suppression does not cause large effects on normal stop codon recognition and so protein function can be restored if the amino acid inserted at the PTC is tolerated or is the wild-type one. Data from several eukaryotic and prokaryotic experimental models suggest that glutamine may be inserted at nonsense UAG or UAA codons, whereas UGA can miscode to tryptophan [Harrell et al., 2002; Nilsson and Ryden-Aulin, 2003; Brooks et al., 2006]. Several studies have shown that the sequence context, i.e. the identity of the stop codon as well as the surrounding sequence, strongly influence readthrough efficiency. In particular, stop codon UGA followed by a $\mathrm{C}$ is most amenable to aminoglycoside-mediated 
readthrough [Manuvakhova et al., 2000; Keeling and Bedwell, 2002]. Low levels of available transcripts due to NMD may represent a limitation to the efficacy of nonsense suppression, and so regulation of this process with specific drugs has been suggested as potential therapeutic target, when combined with the use of readthrough compounds [Linde et al., 2007; Keeling and Bedwell, 2011].

Since the seminal reports in cystic fibrosis, nonsense mutation readthrough has been documented in vitro and in cellular and animal models of different disorders, including Duchenne muscular dystrophy, Hurler's syndrome, diabetes, cystinosis, $\mathrm{X}$-linked retinitis pigmentosa, and ataxia telangiectasia, among others [Barton-Davis et al., 1999; Keeling et al., 2001; Grayson et al., 2002; Lai et al., 2004]. Recessive genetic disorders caused by nonsense mutations are good candidates for readthrough treatment, as small amounts of functionally active protein may prove to be therapeutically relevant. In recent years, different compounds with readthrough activity have been developed based on aminoglycoside structure or identified in high-throughput screens, with the aim of developing a clinically applicable therapy lacking the toxic side effects of long-term use initially observed with aminoglycosides.

\section{Readthrough Drugs}

Gentamicin has been by far the most commonly used aminoglycoside to evaluate suppression therapy in different disease models. However, several studies have analyzed the effect of other aminoglycosides, including geneticin (G418), amikacin, kanamycin, sisomicin, paromomycin, lividomycin, tobramycin, hygromycin and streptomycin, all of them showing variable suppression effects in in vitro and in vivo systems [Manuvakhova et al., 2000; Linde and Kerem, 2008; Popescu et al., 2010]. The results indicated that structurally similar aminoglycosides could result in very different readthrough efficiencies, also depending on the sequence context of the PTC. For some of the aminoglycosides tested, the dose required to achieve a therapeutical effect may be too high for long-term clinical use. In fact, the first human trials carried out with gentamicin in cystic fibrosis and $\mathrm{Du}-$ chenne/Becker muscular dystrophy patients revealed the disadvantages of regular intravenous administration and the risk of nephrotoxicity and ototoxicity as the aminoglycoside presented a narrow therapeutic window [Finkel, 2010]. Several approaches to reduce aminoglyco- side toxicity are to date being explored, among them, coadministration of antioxidants and liposome encapsulation [Schiffelers et al., 2001; Kawamoto et al., 2004]. On the other hand, novel synthetic aminoglycoside derivatives designed to eliminate structural features responsible for toxic side-effects have been developed using a medicinal chemistry approach. These include NB30 and NB54, derived from paromomycin, and NB74 and NB84, both combining structural elements of several aminoglycosides [Nudelman et al., 2009, 2010]. These compounds have greater potency in vitro and in different cellular models than standard aminoglycosides, have little or no antimicrobial activity and show greatly reduced cytotoxicity. Other derivatives such as TC007 were shown to promote readthrough of the SMN protein in spinal muscular atrophy patients' fibroblasts and in an animal model of the disease [Mattis et al., 2009]. Negamycin, a non-aminoglycoside antibacterial dipeptide, has also been described to suppress PTC in Duchenne muscular dystrophy animal and cellular models [Arakawa et al., 2003].

Using a different approach to avoid the limitations of rational design, chemical libraries have been screened using high-throughput assays for nonsense readthrough activity. In this way, the new non-aminoglycoside compound PTC124 was discovered. PTC124 or Ataluren binds eukaryotic ribosomes in a fashion distinct from aminoglycosides, showing potent PTC suppression while preserving the natural termination codon and offering the advantages of having no obvious toxic effects and being orally bioavailable [Welch et al., 2007]. In view of these promising data, the FDA granted orphan drug designation to PTC124 and the results of a phase III clinical trial in cystic fibrosis patients were recently released, showing a trend towards improved lung function (http:// ptct.client.shareholder.com/ReleaseDetail. cfm?ReleaseID=681445).

In other disease states, Duchenne muscular dystrophy, methylmalonic aciduria or haemophilia, clinical trials with Ataluren were discontinued as clinical efficacy was not obvious.

Other non-aminoglycoside compounds identified by high-throughput screens are RTC13 and RTC14, which were shown to suppress nonsense mutations in ataxia telangiectasia patients' cell lines and in myotube cells from a mouse model of Duchenne muscular dystrophy [Du et al., 2009]. These compounds, with a yet unknown mechanism of action, were non-toxic in mammalian cells and did not alter global expression patterns, substantiating their potential further therapeutic development. 
Table 1. Overview of nonsense suppression experiments in cellular and animal models of IMD

\begin{tabular}{|c|c|c|c|c|c|}
\hline \multirow[t]{2}{*}{ Disease (OMIM) } & \multicolumn{2}{|l|}{ Gene } & \multirow[t]{2}{*}{ Drug used } & \multirow[t]{2}{*}{ Effect } & \multirow[t]{2}{*}{ Reference } \\
\hline & name & nonsense mutation(s) & & & \\
\hline $\begin{array}{l}\text { Mucopolysaccharidosis type } \\
\text { I. Hurler syndrome (252800) }\end{array}$ & IDUA & p.Q70X, p.W402X & gentamicin & $\begin{array}{l}\text { increase in enzyme activity/protein } \\
\text { up to } 3 \% \text { of the normal levels; } \\
\text { reduced GAG accumulation and } \\
\text { restoration of lysosomal morphology }\end{array}$ & $\begin{array}{l}\text { Keeling et al. } \\
\text { [2001] }\end{array}$ \\
\hline $\begin{array}{l}\text { Mucopolysaccharidosis type } \\
\text { I. Hurler syndrome (252800) }\end{array}$ & $I D U A$ & $\begin{array}{l}\text { p.Q70X, p.W402X, } \\
\text { p.W180X, p.Y343X, } \\
\text { p.Q400X, p.R268X }\end{array}$ & gentamicin & $\begin{array}{l}\text { cell-line specific increase in } \\
\text { activity, although only residual } \\
\text { levels obtained }\end{array}$ & $\begin{array}{l}\text { Hein et al. } \\
\text { [2004] }\end{array}$ \\
\hline $\begin{array}{l}\text { Mucopolysaccharidosis type } \\
\text { I. Hurler syndrome (252800) }\end{array}$ & Idua & p.W392X & $\begin{array}{l}\text { gentamicin, amikacin, G418, } \\
\text { paromomycin, NB54, NB84 }\end{array}$ & $\begin{array}{l}\text { decrease in GAG tissue accumula- } \\
\text { tion and urine excretion }\end{array}$ & $\begin{array}{l}\text { Wang et al. } \\
{[2011]}\end{array}$ \\
\hline $\begin{array}{l}\text { Infantile neuronal ceroid } \\
\text { lipofuscinosis } \\
\text { Batten disease }(256730)\end{array}$ & PPT1 & $\begin{array}{l}\text { p.R151X, p.L10X, } \\
\text { p.R164X, p.Q291X }\end{array}$ & gentamicin, PTC124 & $\begin{array}{l}\text { modest increase in enzyme activity; } \\
\text { reduced levels of thioesther load and } \\
\text { apoptosis }\end{array}$ & $\begin{array}{l}\text { Sarkar et al. } \\
{[2011]}\end{array}$ \\
\hline Nephropathic cystinosis (606272) & CTNS & p.W138X & gentamicin & cystine depletion & $\begin{array}{l}\text { Helip-Wooley } \\
\text { et al. [2002] }\end{array}$ \\
\hline $\begin{array}{l}\text { Peroxisome biogenesis disorders } \\
(601539)\end{array}$ & PEX2 & p.R119X, p.R125X & G418, PTC124 & $\begin{array}{l}\text { rescue in VLCFA catabolism and } \\
\text { plasmalogen biosynthesis }\end{array}$ & $\begin{array}{l}\text { Dranchak et } \\
\text { al. [2011] }\end{array}$ \\
\hline $\begin{array}{l}\text { Peroxisome biogenesis disorders } \\
(601539)\end{array}$ & PEX12 & p.R180X & G418, PTC124 & $\begin{array}{l}\text { rescue in VLCFA catabolism and } \\
\text { plasmalogen biosynthesis }\end{array}$ & $\begin{array}{l}\text { Dranchak } \\
\text { et al. [2011] }\end{array}$ \\
\hline $\begin{array}{l}\text { Carnitine palmitoyl transferase } 1 \mathrm{~A} \\
\text { deficiency }(255120)\end{array}$ & CPT1A & p.R160X & PTC124, gentamicin & $\begin{array}{l}\text { increase in residual activity up to } \\
45 \% \text { of control levels }\end{array}$ & $\begin{array}{l}\text { Tan et al. } \\
{[2011]}\end{array}$ \\
\hline Methylmalonic aciduria (251000) & MUT & p.R403X & G418, gentamicin & $\begin{array}{l}\text { increase with gentamicin in } \\
\text { reporter gene expression; partial } \\
\text { increase in enzyme activity }\end{array}$ & $\begin{array}{l}\text { Buck et al. } \\
\text { [2009] }\end{array}$ \\
\hline Propionic acidemia (606054) & PCCA & p.R313X, p.S562X & gentamicin, G418, PTC124 & $\begin{array}{l}\text { increase in enzyme activity with } \\
\text { some treatments }\end{array}$ & $\begin{array}{l}\text { Sanchez- } \\
\text { Alcudia et al. } \\
\text { [2012] }\end{array}$ \\
\hline Propionic acidemia (606054) & PCCB & $\begin{array}{l}\text { p.W531X, p.Y314X, } \\
\text { p.G94X }\end{array}$ & gentamicin, G418, PTC124 & $\begin{array}{l}\text { increase in enzyme activity with } \\
\text { some treatments }\end{array}$ & $\begin{array}{l}\text { Sanchez- } \\
\text { Alcudia et al. } \\
\text { [2012] }\end{array}$ \\
\hline
\end{tabular}

\section{Nonsense Suppression in Inherited Metabolic Disease}

Inherited metabolic diseases (IMDs) are each individually rare genetic diseases, although collectively they affect approximately 1/3,000 newborns [Lindner et al., 2011]. The underlying cause of the disease is the functional deficiency of an enzyme or transport protein associated with a metabolic pathway and they are predominantly inherited in autosomal recessive fashion. For many of them there is to date no effective treatment and in all of them a fraction of patients are carriers of nonsense mutations which may be amenable to readthrough using one of the compounds described above. As in other recessive diseases, the presence of small amounts of functional protein have been described to be therapeutically relevant, as observed in knock-out murine models of propionic acidemia, where low enzyme activity levels (10$20 \%$ ) resulting from a low expression transgene significantly improved the outcome preventing neonatal lethality [Miyazaki et al., 2001].

Nonsense Suppression in Inherited Metabolic Disease
There are several examples of successful nonsense suppression in cellular and animal models of IMDs (table 1), starting with mucopolysaccharidosis type I or Hurler syndrome, characterized by lysosomal accumulation of glycosaminoglycans (GAGs) due to the deficiency of the $\alpha$-Lirudonidase enzyme encoded by the IDUA gene. In some populations, up to $76 \%$ of the IDUA mutations are of the nonsense type [Brooks et al., 2006]. In addition, even a small amount of functional $\alpha$-L-irudonidase may attenuate the phenotype [Bunge et al., 1998], thus making the disease a good candidate for suppression therapy. Gentamicin treatment of patients' fibroblasts heterozygous for the common nonsense mutations p.Q70X and p.W402X resulted in the recovery of $\sim 3 \%$ protein and activity levels, along with reduced GAG accumulation and lysosomal vacuolation [Keeling et al., 2001]. In another study, patients' fibroblasts carrying these and/or other nonsense mutations were also subjected to gentamicin treatment, again resulting in a detectable increase in $\alpha$-L-irudonidase activity in most of the cases, although levels obtained were residual compared to normal control or gentamicin- 
treated fibroblasts [Hein et al., 2004]. Furthermore, the authors did not report any substantial change in mRNA levels after gentamicin treatment. In a subsequent study, mouse embryonic fibroblasts derived from the Hurler syndrome mouse model carrier of the IDUA W392X mutation were treated with the conventional aminoglycosides gentamicin, G418, amikacin and paromomycin as well as with the designer derivatives NB54 and NB84. Overall, NB84 was found to be most efficient in partially recovering $\alpha$-L-irudonidase activity and this compound was then tested in vivo in the mouse model, where it was found to result in significantly reduced GAG accumulation and urine excretion [Wang et al., 2011]. Interestingly, brain tissues also showed a $20-40 \%$ decrease in excess GAG storage compared to untreated mice, indicating that these designer drugs can be used to alleviate neurological dysfunction in other disorders caused by nonsense mutations.

In cystinosis, a lysosomal cystine storage disorder, gentamicin treatment of patients' fibroblasts results in prolonged cystine depletion only in cells with nonsense mutations (p.W138X) [Helip-Wooley et al., 2002]. In another report, both gentamicin and PTC124 result in a modest increase in palmitoyl-protein thioestherase- 1 activity in fibroblasts from patients homozygous for nonsense mutations in the PPT1 gene, responsible for infantile neuronal ceroid lipofuscinosis, another lysosomal storage disorder where nonsense mutations are present in $31 \%$ of the patients in the US [Sarkar et al., 2011]. PTC124 showed no cellular toxicity and the treatment reduced the level of thioesther load and apoptotic parameters, which are increased in these cells.

Peroxisome biogenesis disorders are multisystemic autosomal recessive disorders due to mutations in different $P E X$ genes, resulting in the majority of the cases in Zellweger spectrum disorder, while a smaller fraction of cases are classified as rhizomelic chondrodysplasia punctata type 1 . In the latter group, there is a common nonsense mutation, p.L292X in the PEX7 gene accounting for over $60 \%$ of the mutant alleles [Braverman et al., 2000]. In addition, as for lysosomal storage disorders, patients with residual mutant PEX gene function have milder phenotypes, so even a modest functional rescue with readthrough drugs could provide clinical benefits. In skin fibroblasts of Zellweger and rhizomelic chondrodysplasia punctata type 1 patients homozygous or heterozygous for nonsense mutations in different PEX genes subjected to G418 and PTC124 treatment, a dramatic improvement in peroxisomal assembly and function was observed in certain cases [Dranchak et al., 2011].
PTC124 was also tested for its ability to promote readthrough of the p.R160X mutation in the CPT1A gene causing carnitine palmitoyltransferase deficiency resulting in impaired hepatic long-chain fatty acid oxidation and ketogenesis [Tan et al., 2011]. Both with PTC124 and gentamicin, an increase in enzyme activity in patients' fibroblasts was observed, up to levels similar to the ones of a previously studied mild mutation. As in other studies, mRNA levels were unchanged after drug treatment.

Finally, several reports [Buck et al., 2009; FernandezGuerra et al., 2010a; Sanchez-Alcudia et al., 2012] have dealt with the potential of nonsense suppression in branched-chain organic acidurias, a group of disorders that result from a deficiency of specific enzymes involved in the catabolism of branched-chain amino acids, namely maple syrup urine disease, due to a defect in any of the genes $B C K D H A, B C K D H B$ and $D B T$ encoding the catalytic subunits of the branched-chain $\alpha$-ketoacid dehydrogenase complex, methylmalonic aciduria and propionic acidemia, due to the deficiency of methylmalonyl-CoA mutase (MUT gene) and propionyl-CoA carboxylase (PCCA and PCCB genes), respectively, both in the propionate oxidation pathway.

A genomic reporter vector coding for enhanced green fluorescent protein cloned in-frame after the MUT gene with a stop mutation in exon 6 was constructed and stable clones obtained after transfection in HeLa cells. In this system readthrough is monitored by measuring the fluorescence. Treatment of the reporter assay cell lines with gentamicin or a combination of this plus G418 resulted in an increase in fluorescence and in methylmalonyl-CoA mutase activity again providing proof-of-principle of the clinical potential of the readthrough strategy [Buck et al., 2009].

In propionic acidemia, where nonsense mutations are present in approximately $10 \%$ of the patients, several approaches were undertaken to explore the feasibility of readthrough therapy. First, the effect of gentamicin and G418 were tested in an in vitro transcription/translation system for a total of 5 mutations in the PCCA gene and 6 mutations in the $P C C B$ gene, revealing that at least 8 naturally occurring mutations are amenable to suppression by aminoglycosides to a detectable extent [Sanchez-Alcudia et al., 2012]. Representative results for the p.R313X mutation are shown in figure 2 . Second, in silico analysis and transfection experiments were carried out to establish whether the resulting full-length proteins are functional. Finally, using fibroblasts of patients with nonsense mutations, a therapeutically significant increase in enzyme activity for some mutations was demonstrated with 


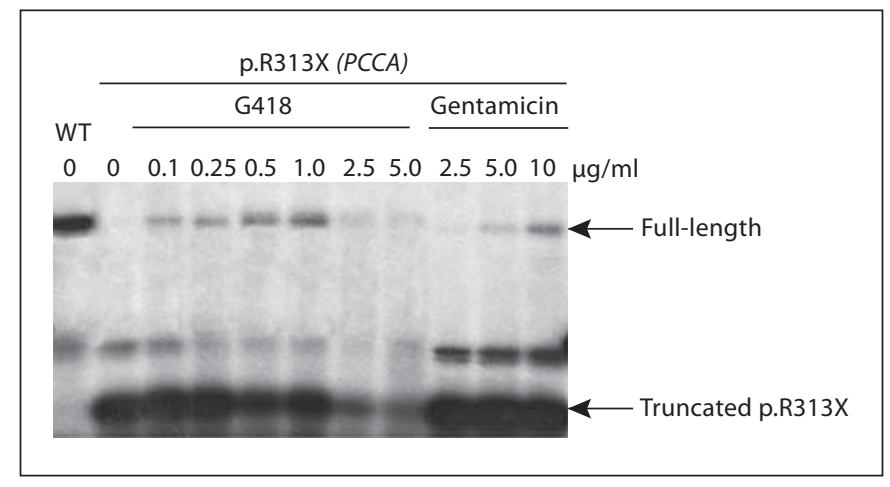

Fig. 2. Effect of aminoglycosides on in vitro readthrough of nonsense mutation p.R313X in the PCCA gene in a coupled transcription-translation assay in the presence of ${ }^{35} \mathrm{~S}$-Met-Cys. Increasing doses of gentamicin and G418 were added to the synthesis reaction resulting in the appearance of a full-length protein. The extra band observed in the translation products presumably corresponds to other open reading frames in the template vector.

gentamicin, G418 or PTC124. Consistent with other studies, UGA codons appeared to have the most efficient readthrough and there were significant differences in the response of different nonsense mutations to the different drugs. This indicates that the spectrum of nonsense mutations as well as the nature and pathophysiology of a disorder may influence the therapeutical outcome with readthrough drugs and should be evaluated in each case.

Preliminary studies have also shown that nonsense mutations, which are particularly frequent in the $B C K D H B$ gene, are also amenable to readthrough, with high levels of full-length protein recovery in vitro and in vivo for mutants carrying the optimal tetranucleotide UGAC [FernandezGuerra et al., 2010a, b].

\section{Conclusions and Future Perspectives}

There is an increasing number of studies providing proof-of-principle of nonsense suppression of aminoglycosides and other compounds in the laboratory and in clinical practice. The results to date favor the feasibility of this approach, providing evidence that this mutationspecific therapy could be applied to many different genetic disorders irrespective of the pathophysiology resulting from the protein dysfunction. There are still some issues to be resolved on a gene by gene basis such as the sequence context of the nonsense mutations identified, available transcript levels and their modulation through the NMD pathway and activity of the resultant fulllength protein in each case. In addition, different delivery strategies are being explored for each specific gene defect, such as transdermal delivery for muscular dystrophies, which could improve treatment specificity maintaining low plasma drug levels and improving patient compliance [Shiozuka et al., 2010]. Most important, present research aims should be focused in the discovery and development of novel compounds with enhanced readthrough activity and reduced toxic side effects, along with their evaluation in clinical trials, with the hope that the carriers of nonsense mutations can be successfully treated in a not too distant future.

\section{Acknowledgements}

This work was supported by grant SAF2010-17272 (to L.R.D) from Ministerio de Ciencia e Innovación. The authors also acknowledge the institutional grant from Fundación Ramón Areces to the Centro de Biología Molecular Severo Ochoa.

\section{References}

-Arakawa M, Shiozuka M, Nakayama Y, Hara T, Hamada M, et al: Negamycin restores dystrophin expression in skeletal and cardiac muscles of mdx mice. J Biochem 134:751-758 (2003).

-Asselta R, Duga S, Spena S, Santagostino E, Peyvandi $F$, et al: Congenital afibrinogenemia: mutations leading to premature termination codons in fibrinogen A alpha-chain gene are not associated with the decay of the mutant mRNAs. Blood 98:3685-3692 (2001).

- Barton-Davis ER, Cordier L, Shoturma DI, Leland SE, Sweeney HL: Aminoglycoside antibiotics restore dystrophin function to skeletal muscles of mdx mice. J Clin Invest 104: 375-381 (1999).
Bedwell DM, Kaenjak A, Benos DJ, Bebok Z, Bubien JK, et al: Suppression of a CFTR premature stop mutation in a bronchial epithelial cell line. Nat Med 3:1280-1284 (1997).

Bellais S, Le Goff C, Dagoneau N, Munnich A, Cormier-Daire V: In vitro readthrough of termination codons by gentamycin in the Stüve-Wiedemann Syndrome. Eur J Hum Genet 18:130-132 (2010).

Braverman N, Steel G, Lin P, Moser A, Moser H, et al: PEX7 gene structure, alternative transcripts, and evidence for a founder haplotype for the frequent RCDP allele, L292ter. Genomics 63:181-192 (2000).
Brooks DA, Muller VJ, Hopwood JJ: Stop-codon read-through for patients affected by a lysosomal storage disorder. Trends Mol Med 12: 367-373 (2006).

Buck NE, Wood L, Hu R, Peters HL: Stop codon read-through of a methylmalonic aciduria mutation. Mol Genet Metab 97:244-249 (2009).

- Bunge S, Clements PR, Byers S, Kleijer WJ, Brooks DA, Hopwood JJ: Genotype-phenotype correlations in mucopolysaccharidosis type I using enzyme kinetics, immunoquantification and in vitro turnover studies. Biochim Biophys Acta 1407:249-256 (1998). 
Chang YF, Imam JS, Wilkinson MF: The nonsense-mediated decay RNA surveillance pathway. Annu Rev Biochem 76:51-74 (2007).

-Dranchak PK, Di Pietro E, Snowden A, Oesch N, Braverman NE, et al: Nonsense suppressor therapies rescue peroxisome lipid metabolism and assembly in cells from patients with specific PEX gene mutations. J Cell Biochem 112:1250-1258 (2011)

Du L, Damoiseaux R, Nahas S, Gao K, Hu H, et al: Nonaminoglycoside compounds induce readthrough of nonsense mutations. J Exp Med 206:2285-2297 (2009).

-Fernandez-Guerra P, Merinero B, Oyarzabal A, Desviat L, Ugarte M, et al: Targeting nonsense mutations in maple syrup urine disease. J Inher Metab Dis 33:S176 (2010a).

-Fernandez-Guerra P, Artuch R, Lambruschini N, Ugarte M, Rodriguez-Pombo P: Native read-through of a nonsense mutation in a maple syrup urine disease patient. J Inher Metab Dis 33:S175 (2010b).

-Finkel RS: Read-through strategies for suppression of nonsense mutations in Duchenne/ Becker muscular dystrophy: aminoglycosides and ataluren (PTC124). J Child Neurol 25:1158-1164 (2010).

- Grayson C, Chapple JP, Willison KR, Webster AR, Hardcastle AJ, et al: In vitro analysis of aminoglycoside therapy for the Arg120stop nonsense mutation in RP2 patients. J Med Genet 39:62-67 (2002).

-Harrell L, Melcher U, Atkins JF: Predominance of six different hexanucleotide recoding signals $3^{\prime}$ of read-through stop codons. Nucleic Acids Res 30:2011-2017 (2002).

Hein LK, Bawden M, Muller VJ, Sillence D, Hopwood JJ, et al: alpha-L-iduronidase premature stop codons and potential read-through in mucopolysaccharidosis type I patients. J Mol Biol 338:453-462 (2004).

-Helip-Wooley A, Park MA, Lemons RM, Thoene JG: Expression of CTNS alleles: subcellular localization and aminoglycoside correction in vitro. Mol Genet Metab 75:128-133 (2002).

Howard M, Frizzell RA, Bedwell DM: Aminoglycoside antibiotics restore CFTR function by overcoming premature stop mutations. Nat Med 2:467-469 (1996).

- Kawamoto K, Sha SH, Minoda R, Izumikawa M, Kuriyama $\mathrm{H}$, et al: Antioxidant gene therapy can protect hearing and hair cells from ototoxicity. Mol Ther 9:173-181 (2004).

-Keeling KM, Bedwell DM: Clinically relevant aminoglycosides can suppress disease-associated premature stop mutations in the IDUA and P53 cDNAs in a mammalian translation system. J Mol Med 80:367-376 (2002).
Keeling KM, Bedwell DM: Suppression of nonsense mutations as a therapeutic approach to treat genetic diseases. Wiley Interdiscip Rev RNA 2:837-852 (2011).

Keeling KM, Brooks DA, Hopwood JJ, Li P, Thompson JN, Bedwell DM: Gentamicinmediated suppression of Hurler syndrome stop mutations restores a low level of alphaL-iduronidase activity and reduces lysosomal glycosaminoglycan accumulation. Hum Mol Genet 10:291-299 (2001).

Kuzmiak HA, Maquat LE: Applying nonsensemediated mRNA decay research to the clinic: progress and challenges. Trends $\mathrm{Mol} \mathrm{Med}$ 12:306-316 (2006).

Lai CH, Chun HH, Nahas SA, Mitui M, Gamo KM, et al: Correction of ATM gene function by aminoglycoside-induced read-through of premature termination codons. Proc Natl Acad Sci USA 101:15676-15681 (2004).

Linde L, Kerem B: Introducing sense into nonsense in treatments of human genetic diseases. Trends Genet 24:552-563 (2008).

Linde L, Boelz S, Nissim-Rafinia M, Oren YS, Wilschanski $\mathrm{M}$, et al: Nonsense-mediated mRNA decay affects nonsense transcript levels and governs response of cystic fibrosis patients to gentamicin. J Clin Invest 117: 683-692 (2007).

Lindner M, Gramer G, Haege G, Fang-Hoffmann J, Schwab KO, et al: Efficacy and outcome of expanded newborn screening for metabolic diseases - report of 10 years from South-West Germany. Orphanet J Rare Dis 6:44 (2011).

Manuvakhova M, Keeling K, Bedwell DM: Aminoglycoside antibiotics mediate context-dependent suppression of termination codons in a mammalian translation system. RNA 6: 1044-1055 (2000).

-Mattis VB, Ebert AD, Fosso MY, Chang CW, Lorson CL: Delivery of a read-through inducing compound, TC007, lessens the severity of a spinal muscular atrophy animal model. Hum Mol Genet 18:3906-3913 (2009).

Miyazaki T, Ohura T, Kobayashi M, Shigematsu Y, Yamaguchi S, et al: Fatal propionic acidemia in mice lacking propionyl-CoA carboxylase and its rescue by postnatal, liver-specific supplementation via a transgene. J Biol Chem 276:35995-35999. (2001).

Mort M, Ivanov D, Cooper DN, Chuzhanova NA: A meta-analysis of nonsense mutations causing human genetic disease. Hum Mutat 29:1037-1047 (2008).
Nilsson M, Ryden-Aulin M: Glutamine is incorporated at the nonsense codons UAG and UAA in a suppressor-free Escherichia coli strain. Biochim Biophys Acta 1627:1-6 (2003).

- Nudelman I, Rebibo-Sabbah A, Cherniavsky M, Belakhov V, Hainrichson M, et al: Development of novel aminoglycoside (NB54) with reduced toxicity and enhanced suppression of disease-causing premature stop mutations. J Med Chem 52:2836-2845 (2009).

- Nudelman I, Glikin D, Smolkin B, Hainrichson M, Belakhov V, et al: Repairing faulty genes by aminoglycosides: development of new derivatives of geneticin (G418) with enhanced suppression of diseases-causing nonsense mutations. Bioorg Med Chem 18:3735-3746 (2010).

- Popescu AC, Sidorova E, Zhang G, Eubanks JH: Aminoglycoside-mediated partial suppression of $M E C P 2$ nonsense mutations responsible for Rett syndrome in vitro. J Neurosci Res 88:2316-2324 (2010).

Sanchez-Alcudia R, Perez B, Ugarte M, Desviat LR: Feasibility of nonsense mutation readthrough as a novel therapeutical approach in propionic acidemia. Hum Mutat 33:973-980 (2012).

- Sarkar C, Zhang Z, Mukherjee AB: Stop codon read-through with PTC124 induces palmitoyl-protein thioesterase-1 activity, reduces thioester load and suppresses apoptosis in cultured cells from INCL patients. Mol Genet Metab 104:338-345 (2011).

-Schiffelers R, Storm G, Bakker-Woudenberg I: Liposome-encapsulated aminoglycosides in pre-clinical and clinical studies. J Antimicrob Chemother 48:333-344 (2001).

-Shiozuka M, Wagatsuma A, Kawamoto T, Sasaki $\mathrm{H}$, Shimada K, et al: Transdermal delivery of a readthrough-inducing drug: a new approach of gentamicin administration for the treatment of nonsense mutation-mediated disorders. J Biochem 147:463-470 (2010).

- Tan L, Narayan SB, Chen J, Meyers GD, Bennett MJ: PTC124 improves readthrough and increases enzymatic activity of the $C P T 1 A$ R160X nonsense mutation. J Inherit Metab Dis 34:443-447 (2011).

-Wang D, Belakhov V, Kandasamy J, Baasov T, Li SC, et al: The designer aminoglycoside NB84 significantly reduces glycosaminoglycan accumulation associated with MPS I-H in the Idua-W392X mouse. Mol Genet Metab 105: 116-125 (2011).

-Welch EM, Barton ER, Zhuo J, Tomizawa Y, Friesen WJ, et al: PTC124 targets genetic disorders caused by nonsense mutations. Nature 447:87-91 (2007). 